\title{
The Role of the Gastrointestinal Tract in Toxigenic Clostridium tetani Infection: A Case-Control Study
}

\author{
Nguyen Van Hao, ${ }^{1,2}$ Nguyen Ngoc My Huyen, ${ }^{2,3}$ Nguyen Thi Han Ny, ${ }^{3}$ Vo Thi Nhu Trang, ${ }^{4}$ Nguyen Van Minh Hoang, ${ }^{2,3}$ \\ Duong Bich Thuy, ${ }^{2}$ Nguyen Thanh Nguyen, ${ }^{2}$ Pham Thi Lieu, ${ }^{3}$ Ha Thi Hai Duong, ${ }^{2}$ Tran Thi Diem Thuy, ${ }^{2}$ Phung Tran Huy Nhat, ${ }^{3}$ \\ Dong Thi Hoai Tam, ${ }^{3}$ Maciej F. Boni, ${ }^{5}$ Lam Minh Yen, ${ }^{3}$ Le Van Tan, ${ }^{3}$ Tran Tan Thanh, ${ }^{3}$ James Campbell, ${ }^{3,6}$ and \\ C. Louise Thwaites ${ }^{3,6 *}$ \\ ${ }^{1}$ University of Medicine and Pharmacy, Ho Chi Minh City, Vietnam; ${ }^{2}$ Hospital for Tropical Diseases, Ho Chi Minh City, Vietnam; ${ }^{3}$ Oxford \\ University Clinical Research Unit, Hospital for Tropical Diseases, Ho Chi Minh City, Vietnam; ${ }^{4}$ Gia Dinh Hospital, Danang, Vietnam; ${ }^{5}$ Center for \\ Infectious Disease Dynamics, Department of Biology, Pennsylvania State University, University Park, Pennsylvania; ${ }^{6}$ Centre for Tropical Medicine \\ and Global Health, University of Oxford, Nuffield Department of Medicine Research Building, University of Oxford, Headington, Oxford, United \\ Kingdom
}

\begin{abstract}
Tetanus arises from wound contamination with Clostridium tetani, but approximately one fifth of patients have no discernable entry wound. Clostridium tetani is culturable from animal feces, suggesting the gastrointestinal tract could be an endogenous reservoir or direct-entry portal, but human data are lacking. In this study of 101 Vietnamese adults with tetanus and 29 hospitalized control subjects, admission stool samples were cultured for C. tetani. Antitetanus toxin antibodies were measured by ELISA. Clostridium tetani toxigenicity was evaluated using polymerase chain reaction and sequencing. Toxigenic $C$. tetani was cultured from stool samples in 50 of $100(50 \%)$ tetanus cases and 12 of $28(42.9 \%)$ control subjects $(P=0.50)$, and stool samples of 44 of $85(52.4 \%)$ tetanus cases with clinically identified wounds compared with 6 of $15(47.6 \%)$ patients without clinically identified wounds $(P=0.28)$. Nine of $12(75 \%)$ control subjects with toxigenic $C$. tetani in their stool samples lacked protective antibody concentrations. These findings fail to show evidence of an association between gastrointestinal $C$. tetani and tetanus infection, but emphasize the importance of increasing vaccination coverage.
\end{abstract}

Tetanus remains a significant public health concern in many low- and middle-income countries. It is caused by the bacterium Clostridium tetani, an anaerobic bacterium able to persist in the environment as a resistant sporulated form. Not all strains of $C$. tetani cause disease, because toxigenicity is conferred by a plasmid containing the tetanus toxin gene. ${ }^{1}$ However toxigenic $C$. tetani strains have been cultured from many environments, including human and animal feces. $^{2-8}$

Wounds contaminated with soil or manure are reported to be at high risk for tetanus acquisition, and management should be determined according to an assessment of exogenous contamination. ${ }^{9}$ Nevertheless, it is possible that gastrointestinal colonization with $C$. tetani represents an important route of endogenous contamination or direct portal of entry. Given the ubiquitous presence of $C$. tetani and the relative rareness of the disease, carriage has also been postulated controversially to cause "natural immunity" from tetanus. ${ }^{10}$

Studies of fecal C. tetani carriage in humans are limited to historical studies and yield conflicting results. Almost 100 years ago, Tenbroeck and Bauer ${ }^{8}$ isolated $C$. tetani capable of causing tetanus in mice in 27 of 78 stool samples from hospitalized patients in China, but Kerrin, ${ }^{7}$ working in the UK, failed to isolate any $C$. tetani from 300 human stool samples despite frequently isolating the toxigenic bacterium from a variety of animals using the same techniques.

In view of continuing uncertainties around the relationship between $C$. tetani carriage, disease, and immunity we carried out a case-control study in 101 adults with tetanus presenting to a tertiary referral hospital in Ho Chi Minh City, Vietnam.

*Address corresponding to Oxford University Clinical Research Unit, Hospital for Tropical Diseases, 764 Vo Van Kiet, District 5, Ho Chin Minh City, Vietman. E-mail: Ithwaites@oucru.org
The study was carried out at the Hospital for Tropical Diseases, a tertiary referral infectious disease center serving southern Vietnam (population, approximately 40 million). All adults older than 15 years admitted to the adult intensive care unit (ICU) at the Hospital for Tropical Diseases with generalized tetanus were eligible for admission to the study. Control subjects were patients admitted to the ICU with other diseases, likely to stay for more than 48 hours, and were matched for age and gender.

After enrollment, baseline characteristics and serum for antitoxin measurement were acquired for all patients. Tetanus cases received a careful examination for entry sites by a dedicated study doctor. This examination included search for oral and aural infection foci. Swabs for C. tetani culture were taken from any identified wound, as described previously. ${ }^{11}$ In all patients, the first stool sample after admission to the ICU was taken for $C$. tetani culture. Cultured C. tetani were tested for the tetanus toxin gene using polymerase chain reaction, as described previously. ${ }^{11}$ When relevant, Sanger sequencing of the polymerase chain reaction products was carried out to compare the sequences of toxincoding genes obtained from the wound swab and the stool sample from the same patients. Tetanus antibody titers were measured by indirect ELISA, which was assayed in duplication using a tetanus toxoid (NIBSC: National Institute for Biological Standards and Control 04/150) and the anti-tetanus immunoglobulin standard 26/488. A cutoff of $0.1 \mathrm{IU} / \mathrm{mL}$ was taken as protective. ${ }^{12,13}$

Our sample size was based on our previous unpublished results of positive C. tetani stool culture rates of $75 \%$ in patients with tetanus and clinically identified entry sites, $90 \%$ with no identified entry site, and $45 \%$ in patients with central nervous system infections. We estimated sample size to detect two differences: 1) cases with known entry sites and control subjects, and 2) those with unknown entry 
sites and control subjects ( $80 \%$ power, two-sided $5 \%$ significance level, and with a case-to-control ratio of two). Our estimation was for 24 tetanus cases without entry sites and 12 control subjects, and 48 tetanus cases with known entry site and 24 control subjects.

Statistics were carried out using R v. 3.5.1 (R Foundation for Statistical Computing, Vienna, Austria). Median and interquartile range values are given for continuous data; number and percentage are provided for categorical data. Proportions were compared using the $\chi^{2}$ test. A $P$ value of $<0.05$ was taken as significant. No corrections were made for multiple comparisons. The study was approved by the Ethical Committee of the Hospital for Tropical Diseases and the Oxford Tropical Research Ethics Committee. All participants, or their representatives, gave written informed consent prior to enrollment.

One hundred-one tetanus cases and 29 control subjects were enrolled between January and September 2018. Baseline demographics are shown in Table 1. Although age and gender were similar between cases and control subjects, control subjects were more likely to be residents of Ho Chi Minh City, admitted directly from the community and less likely to have manual-type occupations.

Stool samples were available from 100 tetanus cases and 28 control subjects. Two participants (one tetanus patient and one control subject before stool samples were obtained). Clostridium tetani was cultured from stool specimens in 75 of $100(75.0 \%)$ tetanus patients and 17 of 28 (60.7\%) control subjects $(P=0.13)$. Fifty $(50 \%)$ tetanus cases and $12(42.9 \%)$ control subjects had bacteria that tested positive for the tetanus toxin gene $(P=0.50)$. There was no difference in the proportion of toxigenic $C$. tetani
TABLE 2

Amino acid differences recorded in toxin coding gene of stool and wound samples of the same tetanus patients

\begin{tabular}{|c|c|c|c|c|}
\hline \multirow[b]{2}{*}{ Patient } & \multirow[b]{2}{*}{ Source } & \multicolumn{3}{|c|}{ Location of toxin coding gene ${ }^{*}$} \\
\hline & & 140 & 248 & 278 \\
\hline \multirow[t]{2}{*}{1} & Stool & $\mathrm{S}$ & $\mathrm{S}$ & Q \\
\hline & Wound & $S$ & $\mathrm{~L}$ & $\mathrm{R}$ \\
\hline \multirow[t]{2}{*}{2} & Stool & $\mathrm{L}$ & $S$ & Q \\
\hline & Wound & $S$ & $S$ & Q \\
\hline \multirow[t]{2}{*}{3} & Stool & $S$ & $\mathrm{~L}$ & NA \\
\hline & Wound & $\mathrm{L}$ & $\mathrm{S}$ & Q \\
\hline \multirow[t]{2}{*}{4} & Stool & $S$ & $\mathrm{~L}$ & $\mathrm{R}$ \\
\hline & Wound & $\mathrm{L}$ & $\mathrm{S}$ & Q \\
\hline \multirow[t]{2}{*}{5} & Stool & $S$ & $\mathrm{~L}$ & $\mathrm{R}$ \\
\hline & Wound & $S$ & $S$ & Q \\
\hline \multirow[t]{2}{*}{6} & Stool & $S$ & $S$ & Q \\
\hline & Wound & $S$ & $\mathrm{~L}$ & $\mathrm{R}$ \\
\hline
\end{tabular}

$*$ Codon position is relative to toxin gene of Clostridium tetani strain E88 (AF528097).

cultured from stool samples in those with known and unknown entry sites: 44 of $85(52.4 \%)$ versus 6 of 15 (47.6\%), respectively $(P=0.28)$.

Fifty-three patients with tetanus $(53 \%)$ had identifiable wounds from which swabs could be taken. Clostridium tetani was cultured from 23 of these, and 19 were classified as toxigenic strains. Seven patients had toxigenic $C$. tetani isolated from both stool sample and wound swab. Of these, six had partial toxin-coding sequences recovered successfully from both wound swabs and stool samples. These were different in one to three amino acids (Table 2).

Antitoxin antibody titers greater than the protective threshold were measured in 7 of 29 (24.1\%) control subjects and 9 of 101 tetanus cases $(8.9 \%)(P=0.03)$. Of these 9 tetanus

TABLE 1

Baseline characteristics of case and control populations

\begin{tabular}{|c|c|c|c|c|c|}
\hline \multirow[b]{2}{*}{ Characteristic } & \multicolumn{2}{|c|}{ Tetanus cases } & \multicolumn{2}{|r|}{ Control subjects } & \multirow[b]{2}{*}{$P$ value } \\
\hline & $N$ & Count (\%) or median (IQR) & $N$ & Count (\%) or median (IQR) & \\
\hline Female & 101 & $21(20.8)$ & 29 & $6(20.7)$ & 0.99 \\
\hline $\begin{array}{l}\text { History of previous } \\
\text { vaccination }\end{array}$ & 101 & $2(2.0)$ & 29 & $1(3.4)$ & 0.649 \\
\hline $\begin{array}{l}\text { Direct community } \\
\text { admission }\end{array}$ & 101 & $16(15.8)$ & 29 & $12(41.4)$ & 0.003 \\
\hline $\begin{array}{l}\text { Resident of Ho Chi } \\
\text { Minh City }\end{array}$ & 16 & $16(15.8)$ & 13 & $13(44.8)$ & 0.002 \\
\hline $\begin{array}{l}\text { Manual occupation: } \\
\text { laborer, farmer, } \\
\text { mechanic }\end{array}$ & 55 & $42(76.3)$ & 27 & $10(37.0)$ & $<0.001$ \\
\hline $\begin{array}{l}\text { Requiring mechanical } \\
\text { ventilation }\end{array}$ & 101 & $58(57.4)$ & 29 & $21(72.4)$ & 0.145 \\
\hline $\begin{array}{l}\text { Survived to hospital } \\
\text { discharge }\end{array}$ & 101 & $95(94.1)$ & 28 & $18(62.1)$ & $<0.001$ \\
\hline Age (years) & 101 & $52(43-64)$ & 29 & $53(37-61)$ & 0.483 \\
\hline $\begin{array}{l}\text { Sequential Organ } \\
\text { Failure Score }\end{array}$ & 101 & $0(0-1)$ & 29 & $4(3-8)$ & $<0.001$ \\
\hline No. of comorbidities & 101 & $0(0-1)$ & 29 & $1(0-2)$ & $<0.001$ \\
\hline $\begin{array}{l}\text { ICU length of stay } \\
\text { (days) }\end{array}$ & 101 & $15(8-23)$ & 29 & $6(3-10)$ & $<0.001$ \\
\hline $\begin{array}{l}\text { Hospital length of stay } \\
\text { (days) }\end{array}$ & 101 & $25(18-35)$ & 28 & $10.5(8-17)$ & $<0.001$ \\
\hline \multicolumn{3}{|c|}{ Diagnosis $\quad$ Tetanus $(N=101)$} & \multicolumn{3}{|c|}{$\begin{array}{l}\text { Dengue }(N=4) \text {, } \\
\text { encephalitis/meningitis }(N=2) \text {, } \\
\text { encephalopathy }(N=2) \text {, } \\
\text { pneumonia }(N=7) \text {, } \\
\text { septic shock }(N=13) \text {, typhus }(N=1)\end{array}$} \\
\hline
\end{tabular}


cases, 8 were documented to have received antitoxin prior to blood sampling for antibodies, and one had been transferred from another hospital where prior antitoxin administration could not be excluded. Overall 9 of 12 (75\%) control subjects with toxigenic $C$. tetani in their stool samples lacked protective antibodies. The median age of control subjects with protective antibodies was less than those without: 40 years (IQR, 35-44 years) and 57 years (IQR, 48-62 years), respectively $(P=0.047)$.

Our principal findings are that $C$. tetani was cultured frequently from study participants' stool samples, and approximately half of the participants' stool samples contained toxigenic strains, with a comparable detection rate between the cases and control subjects. High isolation rates occurred in patients with tetanus, who are often manual workers from rural locations, but we also observed high rates in control subjects. A potential limitation of our study is that control subjects, although matched for age and gender, were not matched for occupation. We found that control subjects were more likely to be Ho Chi Minh City residents with a lower likelihood of working in manual occupations. However, in view of our findings of high $C$. tetani isolation rates in control subjects, our study may indicate that $C$. tetani carriage is common in both rural and urban populations in Vietnam.

We found that $15 \%$ of tetanus cases had unknown entry sites. This number is less than previously reported (approximately $25 \%)^{14}$ and may be the result of the very careful search we made for these sites in our study. We did not find evidence supporting increased gastrointestinal isolation of C. tetani in patients with unknown entry sites, which suggests the gastrointestinal tract is not an important portal of entry for $C$. tetani. Because the majority of clinically identified entry sites in our study were small minor wounds or abrasions, it is possible that wounds in those with unknown entry sites may have healed before admission. Although most tetanus cases had toxigenic $C$. tetani isolated from stool samples, only a small number had toxigenic $C$. tetani isolated concurrently from clinically identified wounds. This may be the result of a failure to identify correctly the true entry portal or sampling after initial wound cleansing. The dissimilarities in genetic sequences between individuals' isolates suggests wound and stool strains were often different; however, we were only able to obtain genetic sequencing in paired samples in a small number of patients.

It is possible that the $C$. tetani cultured from stool samples represents only the brief transit of ingested $C$. tetani spores through the gastrointestinal tract. Because we did not collect longitudinal stool samples, we cannot confirm whether persistent carriage was occurring. Literature reports have noted that $C$. tetani was cultured for only 4 days in stool samples from horses and mice after being fed $C$. tetani spores, ${ }^{6,7}$ but it was cultured for several months in Chinese hospital patients fed a "hospital diet."

The majority of the participants in our study lacked protective antibody concentrations of anti-tetanus toxoid antibody. Our use of ELISA for antibody measurement is a limitation of this study, because ELISA is subject to inaccuracy and specificity issues, especially at low antibody concentrations. As a result we used the recommended greater "protective threshold" for ELISA of $0.1 \mathrm{IU} / \mathrm{mL}$, as opposed to $0.01 \mathrm{IU} / \mathrm{mL}$ recommended for toxin neutralization assay. ${ }^{10}$ Using this cutoff, only $24 \%$ of control subjects were found to have protective antibody concentrations, which is consistent with results of a previous sero-surveillance study from Ho Chi Minh City in which approximately $25 \%$ of males in this age group had protective antibody levels. ${ }^{12}$ Our findings also correspond to current vaccine policy in Vietnam, where immunization programs for infants and women of childbearing age have achieved high coverage rates; however, there are no programs for men and for adults born before immunization programs commenced, and there is limited access to later childhood tetanus-diphtheria boosters in many places. ${ }^{15} \mathrm{We}$ note that nine cases of tetanus had antibody levels classified as "protective," but a retrospective review of these cases revealed that eight had antitoxin documented prior to sampling for antibody measurement and the remaining case had been transferred from another hospital, where preceding antitoxin administration could not be excluded definitively.

We demonstrated the presence of toxigenic $C$. tetani in stool samples from a significant number of patients hospitalized for tetanus or other diseases. The majority of patients also lacked protective antibody levels against tetanus. Given the high frequency of toxigenic $C$. tetani present in stool samples, our findings emphasize that vaccination should remain the major strategy in tetanus prevention.

Received February 5, 2021. Accepted for publication March 29, 2021.

Published online June 28, 2021.

Acknowledgments: We thank Ray Borrow, Abigail Bell, and Ezra Linley for advice regarding antibody measurements; the Adult Intensive Care Unit Staff at the Hospital for Tropical Diseases for assistance in implementing the study; and Le Thanh Hoang Nhat, Oxford University Clinical Research Unit, Biostatistical Department, for statistical advice.

Financial support: This study is supported by the Wellcome Trust $(089276 / B / 09 / 7)$. C. L.T. is supported by the Wellcome Trust $(107367 / Z / 15 / Z)$ and L. V. T. is supported by the Wellcome Trust (204904/Z/16/Z).

Authors' addresses: Nguyen Van Hao, University of Medicine and Pharmacy, Ho Chi Minh City, Vietnam, and Hospital for Tropical Diseases, Ho Chi Minh City, Vietnam, E-mail: dr_nguyenvanhao@ump. edu.vn. Nguyen Ngoc My Huyen and Nguyen Van Minh Hoang, Hospital for Tropical Diseases, Ho Chi Minh City, Vietnam, and Oxford University Clinical Research Unit, Hospital for Tropical Diseases, Ho Chi Minh City, Vietnam, E-mails: huyennm@oucru.org and hoangnvm@oucru.org. Nguyen Thi Han Ny, Pham Thi Lieu, Phung Tran Huy Nhat, Dong Thi Hoai Tam, Lam Minh Yen, Le Van Tan, Tran Tan Thanh, Oxford University Clinical Research Unit, Hospital for Tropical Diseases, Ho Chi Minh City, Vietnam, E-mails: nynth@oucru.org, lieupt@oucru.org, nhatpth@oucru.org, tamdth@ oucru.org, yenlm@oucru.org, tanlv@oucru.org, and thanhtt@oucru. org. Vo Thi Nhu Trang, Gia Dinh Hospital, Danang, Vietnam, E-mail: vothinhutrang.113@gmail.com. Duong Bich Thuy, Nguyen Thanh Nguyen, Ha Thi Hai Duong, and Tran Thi Diem Thuy, Hospital for Tropical Diseases, Ho Chi Minh City, Vietnam, E-mails: duongthuyicu@gmail.com, nguyenicu@gmail.com, haduong200385@yahoo.com.vn, and thuytranbvbnd@gmail.com. Maciej F. Boni, Center for Infectious Disease Dynamics, Department of Biology, Pennsylvania State University, University Park, PA, E-mail: mfb9@psu.edu. James Campbell and C. Louise Thwaites, Oxford University Clinical Research Unit, Hospital for Tropical Diseases, Ho Chi Minh City, Vietnam, and Centre for Tropical Medicine and Global Health, University of Oxford, Nuffield Department of Medicine Research Building, University of Oxford, Headington, Oxford, United Kindgom, E-mails: jcampbell@oucru.org and Ithwaites@oucru.org.

This is an open-access article distributed under the terms of the Creative Commons Attribution (CC-BY) License, which permits 
unrestricted use, distribution, and reproduction in any medium, provided the original author and source are credited.

\section{REFERENCES}

1. Brüggemann $H$, Brzuszkiewicz E, Chapeton-Montes D, Plourde L, Speck D, Popoff MR, 2015. Genomics of Clostridium tetani. Res Microbiol 166: 326-331.

2. Popoff MR, 2020. Tetanus in animals. J Vet Diagn Invest 32: 184-191.

3. Ebisawa I, Takayanagi M, Kurata M, Kigawa M, 1986. [Density and distribution of $C$. tetani in the ground]. Kansenshogaku Zasshi 60: 277-282.

4. Sanda I, Nishida S, 1965. Isolation of Clostridium tetani from soil. J Bacteriol 89: 626-629.

5. Dubovsky BJ, Meyer KF, 1922. The occurrence of $C$. tetani in soil and on vegetables. J Infect Dis 31: 614-616.

6. Wilkins CA et al., 1988. tetani Occurrence of Clostridium tetani in soil and horses. S Afr Med J 73: 1987-1989.

7. Kerrin JC, 1928. The distribution of $C$. tetani in the intestines of animals. Br J Exp Pathol 1929: 370-373.
8. Tenbroeck C, Bauer J, 1922. The tetanus bacillus as an intestinal saprophyte in man. $J$ Exp Med 36: 261-271.

9. Yen LM, Thwaites CL, 2019. Tetanus. Lancet 393: 1657-1668.

10. Basta N, Borrow R, Miller E, 2018. WHO Immunological Basis for Immunization Series Module 3 Tetanus Update 2018. Geneva, Switzerland: World Health Organization.

11. Campbell $\mathrm{Jl}$ et al., 2009. Microbiologic characterization and antimicrobial susceptibility of Clostridium tetani isolated from wounds of patients with clinically diagnosed tetanus. Am J Trop Med Hyg 80: 827-831.

12. Thuy DB et al., 2016. Tetanus in southern Vietnam: current situation. Am J Trop Med Hyg 96: 7-9.

13. Ibinda $\mathrm{F}$ et al., 2015. Incidence and risk factors for neonatal tetanus in admissions to Kilifi County Hospital, Kenya. PLoS Negl Trop Dis 9: e0003466.

14. Thwaites $C L$ et al., 2004. Impact of improved vaccination programme and intensive care facilities on incidence and outcome of tetanus in southern Vietnam, 1993-2002. Trans $R$ Soc Trop Med Hyg 98: 671-677.

15. World Health Organization, 2020. WHO Vaccine-Preventable Diseases: Monitoring System: 2020 Global Summary. Available at: https://apps.who.int/immunization_monitoring/ globalsummary. Accessed May 11, 2021. 